\title{
Bauer, Dieter R., Herbers, Klaus, Signori, Gabriela, Patriotische Heilige. Beiträge zur Konstruktion religiöser und politischer Identitäten in der Vormoderne
}

\section{Klaus Krönert}

\section{(2) OpenEdition}

\section{Journals}

Édition électronique

URL : http://journals.openedition.org/ifha/1580

DOI : $10.4000 /$ ifha. 1580

ISSN : 2198-8943

Éditeur

IFRA - Institut franco-allemand (sciences historiques et sociales)

\section{Référence électronique}

Klaus Krönert, « Bauer, Dieter R., Herbers, Klaus, Signori, Gabriela, Patriotische Heilige. Beiträge zur Konstruktion religiöser und politischer Identitäten in der Vormoderne », Revue de I'IFHA [En ligne], Date de recension, mis en ligne le 01 janvier 2008, consulté le 22 septembre 2020. URL : http:// journals.openedition.org/ifha/1580 ; DOI : https://doi.org/10.4000/ifha.1580

Ce document a été généré automatiquement le 22 septembre 2020.

(CIFHA 


\title{
Bauer, Dieter R., Herbers, Klaus, Signori, Gabriela, Patriotische Heilige. Beiträge zur Konstruktion religiöser und politischer Identitäten in der Vormoderne
}

\author{
Klaus Krönert
}

1 Malgré d'innombrables études, les saints restent un sujet de recherche très complexe, et pour cause : personnages historiques, intervenant dans la vie quotidienne après leur mort, intercesseurs auprès de Dieu, sujets de biographie sainte, objets de vénération et de réflexions théologiques, ils pouvaient aussi être fédérateurs de sentiments patriotiques et devenir de véritables symboles identitaires. Cependant loin d'être atemporels et immuables, ces symboles sont liés à des personnes et des sociétés, qui changent au fil du temps, et ils ont par-là, eux aussi, une histoire. C'est le thème qui est au centre du présent recueil d'articles. Étant donné que les seize études, ici réunies, couvrent, pour la plupart, le Moyen Âge et l'époque moderne et qu'elles sont consacrées autant à l'Europe occidentale qu'à l'Europe de l'Est et même à l'Égypte et au Mexique, le terme " patrie » doit être compris dans un sens très large couvrant selon les cas, des pays, des régions, des villes ou des communautés.

2 Le premier article de G. Signori fait office d'introduction et donne au recueil une certaine unité : elle analyse l'usage du terme patria à travers les trois grandes époques, l'Antiquité, le Moyen Âge et l'époque moderne, elle discute de manière critique quelques controverses, dont celle qui remonte à E. Kantorowicz et qui s'attache à déterminer si l'idée de mourir pour la patrie précéda l'idéal martyr ou vice versa. À l'appui de ces remarques d'ordre général, l'auteur présente deux études de cas sur Gervais et Protais à Breisach et le rôle de Marie en tant que sainte protectrice de Strasbourg. Les autres contributions, très éclectiques, s'ordonnent autour des thèmes suivants : G. Tüskés et E. Knapp examinent le culte de Stéphane de Hongrie dès ses 
débuts au XIe s. jusqu'à l'époque moderne, C. Scholz s'intéresse à la vénération de Démétrios de Thessalonique durant tout le Moyen Âge, K. Herbers présente les cultes des saints en Espagne du VIIIe au Xe s., U. Kleine essaie de comprendre comment les cultes ont structuré l'espace rural dans les régions du Rhin et de la Moselle, et V. Souche-Hazebrouck se demande qui, des saints ou des textes hagiographiques, est patriotique dans le Brabant de la fin du Moyen Âge. Ensuite, A.T. Hack donne une vision d'ensemble des cultes chez les hussites des XVe et XVIe s., H. Behlmer travaille sur les « saints patriotiques " en Égypte et leur vénération jusqu'à l'époque moderne, C. Dartmann s'intéresse aux saints patrons de Milan et de Florence au Moyen Âge central, K. Böse présente des Vies de saints illustrées provenant de la Toscane du XVe s., T. Maissen examine les changements dans la vénération de Félix et Regula, saints patrons de Zurich, durant l'époque de la Réforme, M. Kloft et F. Schmieder dessinent, avec une double approche historique et théologique, une topographie sacrale de Francfort-surle-Main depuis la fondation de la ville jusqu'à l'époque moderne, K. Schreiner décrit la force identitaire de la Vierge Marie dans de nombreuses villes et régions, essentiellement de tradition germanique, et S. Hensel montre comment la Vierge de Guadalupe est devenue la sainte nationale du Mexique. Enfin, C. Schmitt présente le culte de Bernard de Baden à l'époque moderne et L. M. Koldau s'intéresse à la vénération patriotique de Boniface dans l'Allemagne du XIXes.

Klaus Krönert (Université Charles-de-Gaulle - Lille III) 